\title{
Uso do "Swab" de Algodão para Colpocitologia
}

\author{
Use of the Cotton Swab in Cervical Cytology
}

Álvaro Luiz Lage Alves

RESUMO

\begin{abstract}
Objetivos: investigar se a adição do swab de algodão à espátula de Ayre e o seu prévio umedecimento com solução salina fisiológica aumentam a obtenção de células endocervicais nos esfregaços colpocitológicos.

Métodos: foi realizado um estudo diagnóstico, randômico e simples cego envolvendo três técnicas de colheita (espátula de Ayre, combinação espátula de Ayre-swab de algodão seco e combinação espátula de Ayre-swab de algodão úmido). Foram avaliados 307 esfregaços preparados por estudantes de Medicina e residentes de Ginecologia e Obstetricia.

Resultados: não houve aumento significativo na obtenção de células endocervicais (colunares e/ou metaplásicas), nem com a adição do "swab" seco ( $p=0,2)$, tampouco com a do swab umidecido $(p=0,8)$.

Conclusões: concluiu-se que, principalmente quando as colheitas forem realizadas por profissionais em treinamento e na ausência de outro dispositivo de coleta endocervical mais eficiente, é mais econômico utilizar apenas a espátula de Ayre no preparo do esfregaço.
\end{abstract}

PALAVRAS-CHAVE: Colpocitologia. Colo uterino: lesões pré-neoplásicas. Câncer: rastreamento.

\section{Introdução}

O câncer de colo uterino é o segundo mais comum entre as mulheres no Brasil e no mundo. No ano de 1998 foi prevista a ocorrência de 21.725 casos novos e de 6.815 óbitos entre as mulheres brasileiras ${ }^{1}$.

O rastreamento de pacientes com lesões precursoras e câncer de colo uterino é comprovadamente eficaz quando realizado por meio da colpocitologia corada pelo método de Papanicolaou tornando imprescindivel o seu amplo emprego ${ }^{2,3}$. A confiabilidade da amostra é dependente da realização da colheita na zona de transformação e o consenso tem sido considerar satisfatórios aqueles esfregaços apresentando células escamosas acompanhadas de células endocervicais colunares ou de células metaplásicas ${ }^{4,5}$. A qualidade da amostra é também diretamente relacionada com a habilidade de quem realiza a colheita e com os

Departamento de Medicina Social. Faculdade de Ciências Médicas de Minas Gerais (FCMMG).

Correspondência:

Álvaro Luiz Lage Alves

Faculdade de Ciências Médicas de Minas Gerais - Internato Rural

Alameda Ezequiel Dias, 275 - Centro

Caixa Postal 1756

30130-110 - Belo Horizonte - MG dispositivos utilizados ${ }^{6}$. A maioria dos autores afirma que a escova endocervical (modelo Cytobrush) é o melhor instrumento para a amostragem da endocérvice ${ }^{7}$. Afirmam também que a combinação espátula de Ayre-escova endocervical é a melhor técnica para se obter um esfregaço satisfatório ${ }^{7,8}$.

O Internato Rural da Faculdade de Ciências Médicas de Minas Gerais - FCMMG se iniciou em 1989. Desde então, a equipe vem buscando a participação ativa na construção do Sistema Único de Saúde - SUS, por meio da tentativa de ampliar a capacidade de resolução das unidades de saúde e de buscar o estreitamento da relação entre elas (sistema de referência e contra-referência) e a sociedade. Na prática tocoginecológica enfrentamos, invariavelmente, a falta de acesso até mesmo às tecnologias mais simples e baratas. No rastreamento do câncer de colo uterino, a dificuldade de ampla aplicação da escova endocervical nos induz a investigar a eficácia de outros dispositivos para a colheita citológica endocervical.

O swab de algodão é utilizado há várias décadas no preparo de amostras colpocitológicas, principalmente da endocérvice ${ }^{9}$. O presente estudo investigou se a adição do swab de algodão (utilizado no preparo do esfregaço endocervical) à espátula de Ayre e o seu prévio umidecimento realmente melhoram a obtenção de células endocervicais nos esfregaços colpocitológicos. 


\section{Pacientes e Métodos}

O presente trabalho foi autorizado pela Comissão de Ética em Pesquisa da Instituição. As pacientes foram examinadas por estudantes de Medicina e residentes de Ginecologia e Obstetrícia durante um mutirão de prevenção do câncer de colo uterino realizado no município de Bambuí, MG nos dias 25 e 26 de outubro de 1997. Elas foram aleatoriamente distribuídas em três grupos de técnicas de colheita. Aquelas alocadas no grupo I tiveram seus esfregaços preparados unicamente pela espátula de Ayre (rotação de $360^{\circ}$ na ectocérvice). No grupo II, os esfregaços foram preparados com a combinação espátula de Ayre-swab de algodão seco (Steri-gamma-swab I). No grupo III, os esfregaços foram coletados com a combinação espátula de Ayreswab de algodão umidecido com solução salina fisiológica. Nos grupos II e III, a coleta ectocervical foi realizada antes da endocervical e ambas com rotação de $360^{\circ}$. O material foi espalhado uniformemente em lâmina de vidro única.

Foram incluidas 307 mulheres no menacme e pós-menopausa, independente da paridade. Foram excluidas as gestantes, as que apresentavam sangramento e as que haviam utilizado medicação intravaginal, duchas ou coito previamente ao dia da coleta. A idade das mulheres variou de 19 a 74 anos com média de 41,9 . A maioria $(96,1 \%)$ já havia engravidado e apenas $13(4,2 \%)$ eram nuliparas. Oitenta e quatro pacientes $(27,4 \%)$ já não apresentavam ciclos menstruais. A idade de início da atividade sexual, obtida de 295 mulheres, variou de 13 a 37 anos com média de 19,9. A maioria das mulheres (64,4\% de 306 investigadas) nunca havia se submetido ao exame preventivo do câncer de colo uterino.

Os 307 esfregaços foram examinados por um único citotécnico, sob supervisão de docentes de Citopatologia da FCMMG. Eles não foram informados sobre as técnicas utilizadas no preparo dos esfregaços (ensaio simples cego). Foram avaliadas e comparadas: a descamação do epitélio escamoso, as proporções de esfregaços apresentando células endocervicais colunares e/ou metaplásicas e a presença e grau de sangramento. De acordo com o extrato de origem das células, a descamação do epitélio escamoso foi classificada em superficial/intermediária, intermediária/ profunda e profunda. O sangramento foi classificado em ausente, pouco ou moderado/abundante.

Os dados foram inseridos no Programa Epi Info, versão 6.04b. Para comparação dos métodos, utilizouse o teste do $\chi^{2}$ com valores de Yates corrigido.

\section{Resultados}

No grupo I (espátula de Ayre) foram obtidos 124 esfregaços $(40,4 \%)$, no grupo II (combinação espátula de Ayre-swab de algodão seco) 79 (25,7\%) e no grupo III (combinação espátula de Ayre-swab de algodão umidecido) 104 (33,9\%).

Não houve nenhum esfregaço considerado inadequado para avaliação assim como nenhuma lesão pré-neoplásica foi rastreada.

O desempenho dos três métodos na obtenção de células escamosas e de células endocervicais colunares e/ou metaplásicas é apresentado na Tabela 1. Com a espátula de Ayre foram obtidos 102 (82,3\%) esfregaços apresentando descamação de células escamosas superficiais e intermediárias, 16 deles $(12,9 \%)$ apresentaram descamação escamosa intermediária e profunda, $6(4,8 \%)$ apenas descamação profunda e $77(62,1 \%)$ apresentavam células endocervicais colunares e/ou metaplásicas. Com a combinação espátula de Ayre-swab de algodão seco obtivemos 60 esfregaços apresentando descamação de células escamosas superficiais e intermediárias (75,9\%), 16 descamação escamosa intermediária e profunda (20,3\%), 3 apresentando apenas descamação profunda $(3,8 \%)$ e 57 apresentando células endocervicais colunares e/ou metaplásicas (72,2\%). Com a combinação espátula de Ayre-swab de algodão úmido o resultado foi 91 esfregaços apresentando descamação de células escamosas superficiais e intermediárias $(87,5 \%), 12$ apresentando descamação escamosa intermediária e profunda $(11,5 \%), 1$ apresentando apenas descamação profunda $(1,0 \%)$ e 67 apresentando células endocervicais colunares e/ ou metaplásicas $(64,4 \%)$.

Tabela 1 - Distribuição dos esfregaços preparados com os três métodos quanto à obtenção de células escamosas e de células endocervicais colunares e/ou metaplásicas.

\begin{tabular}{lccc}
\hline Esfregaços apresentando: & $\begin{array}{c}\text { Espátula de Ayre* } \\
\mathbf{( \% )}\end{array}$ & $\begin{array}{c}\text { Combinação espátula } \\
\text { de Ayre-"swab" de } \\
\text { algodão seco** (\%) }\end{array}$ & $\begin{array}{c}\text { Combinação espátula } \\
\text { de Ayre-“swab" de } \\
\text { algodão úmido** }(\%)\end{array}$ \\
\hline Descamação superficial e intermediária & $102(82,3)$ & $60(75,9)$ & $91(87,5)$ \\
Descamação intermediária e profunda & $16(12,9)$ & $16(20,3)$ & $12(11,5)$ \\
Descamação profunda & $6(4,8)$ & $3(3,8)$ & $1(1,0)$ \\
Células endocervicais colunares e/ou metaplásicas & $77(62,1)$ & $57(72,2)$ & $67(64,4)$ \\
\hline
\end{tabular}

* Grupo 1

** Grupo 2

*** Grupo 3 
Não houve diferença estatisticamente significativa entre os métodos com relação à descamação de células escamosas provenientes dos diversos extratos $\left(\chi^{2}=6,11 ; p=0,2\right)$. Também não houve diferença estatisticamente significativa entre os três métodos com relação às proporções de esfregaços apresentando células endocervicais colunares e/ou metaplásicas $\left(\chi^{2}=2,23 ; \mathrm{p}=0,3\right)$. Os valores estatísticos obtidos do confronto entre os métodos se encontram representados na Tabela 2. Ao compararmos a espátula de Ayre e a combinação espátula de Ayre-swab de algodão seco quanto às proporções de esfregaços apresentando células endocervicais colunares e/ou metaplásicas, encontramos $\chi^{2}=1,75$ e valor $p=0,2$. Ao efetuarmos a mesma comparação entre a espátula de Ayre e o swab de algodão úmido, encontramos $\chi^{2}=0,05$ e valor $\mathrm{p}=0,8$. A mesma comparação entre as combinações espátula de Ayre-swab de algodão seco e espátula de Ayre-swab de algodão úmido revelou $\chi^{2}=0.9$ e valor $\mathrm{p}=0,3$.

Tabela 2 - Distribuição dos valores estatísticos encontrados na comparação entre os métodos quanto à proporção de esfregaços contendo células endocervicais colunares e/ou metaplásicas

\begin{tabular}{lcc}
\hline Métodos & $\mathbf{n}(\%)$ & $\chi^{2}$ \\
\hline EA vs. & $77(62,1)$ & 1,75 \\
EA + Swab seco & $57(72,2)$ & 0,2 \\
EA vs. & $77(62,1)$ & 0,05 \\
EA + Swab úmido & $67(64,4)$ & 0,8 \\
EA + Swab seco vs. & $57(72,2)$ & 0,9 \\
EA + Swab úmido & $67(64,4)$ & 0,3
\end{tabular}

$E A=$ Espátula de Ayre

A distribuição dos esfregaços quanto à presença e grau de sangramento se encontra representada na Tabela 3. Ao compararmos os grupos, não encontramos diferença estatisticamente significativa $\left(\chi^{2}=2,44 ; p=0,7\right)$.

Tabela 3 - Distribuição dos esfregaços preparados pelos três métodos quanto à presença e grau de sangramento.

\begin{tabular}{lccr}
\hline Grau & Espátula de Ayre* & $\begin{array}{c}\text { Combinação espátula } \\
\text { de Ayre-"swab" de } \\
\text { algodão seco** }\end{array}$ & $\begin{array}{c}\text { Combinação espátula } \\
\text { de Ayre-"swab" de } \\
\text { algodão úmido*** }\end{array}$ \\
\hline Ausente & $56(45,2 \%)$ & $28(35,4 \%)$ & $44(42,3 \%)$ \\
Pouco & $62(50,0 \%)$ & $47(59,5 \%)$ & $53(51,0 \%)$ \\
Moderado/Abundante & $6(4,8 \%)$ & $4(5,1 \%)$ & $7(6,7 \%)$ \\
Total & 124 & 79 \\
\hline
\end{tabular}

* Grupo 1

** Grupo 2

*** Grupo 3

\section{Discussão}

Os dados da literatura ainda são inconclusivos a respeito dos componentes endocervicais como medida de adequação da amostra. Os resultados falso-negativos e o desenvolvimento de atipias em mulheres cujos esfregaços prévios não continham células endocervicais colunares são fortes motivos para concluir que a presença destas células é imprescindivel para que a amostra colpocitológica 
seja considerada adequada ${ }^{10}$.

Ao avaliar a composição celular e a amostra da zona de transformação, a classificação de Bethesda (Sistema Bethesda) considera que uma amostra é definida como completamente satisfatória quando contém células escamosas e células endocervicais colunares ou escamosas metaplásicas. No Sistema Bethesda se afirma que os estudos cruzados têm repetidamente demonstrado que esfregaços contendo células endocervicais colunares têm uma freqüência significativamente mais alta e um maior grau de detecção de anormalidades escamosas que esfregaços nos quais estas células estão ausentes. Afirma-se também que a revisão de esfregaços positivos e negativos de mulheres com lesão intraepitelial escamosa de alto grau e carcinoma tem demonstrado que as amostras positivas são mais prováveis do que as negativas de apresentarem células metaplásicas ou ambas (células metaplásicas e endocervicais colunares) ${ }^{4}$. Observou-se ainda que as observações indicam que espécimes sem componentes endocervicais muitas vezes podem detectar epitélios escamosos anormais e que, até a presente data, os estudos longitudinais a curto prazo não têm demonstrado um aumento da freqüência de tais lesões no acompanhamento de mulheres em cujos esfregaços faltavam células endocervicais colunares ${ }^{4}$.

No presente estudo, o material foi coletado por profissionais em treinamento (estudantes de Medicina e residentes de Ginecologia e Obstetrícia). $O$ raspado ectocervical foi efetuado antes do endocervical para evitar o excesso de sangue na amostra quando se realiza a colheita em sequência inversa ${ }^{11}$. O preparo dos esfregaços em lâmina única se baseou na afirmativa de que este método é tão eficaz quanto o método de dupla lâmina e possui a vantagem de reduzir os custos e o tempo de trabalho no laboratório ${ }^{12}$. Apesar da amostra estudada não ter sido suficiente para efetuarmos a comparação da capacidade dos métodos na detecção de lesões pré-neoplásicas, utilizamos os critérios mais aceitos para avaliação da adequação dos esfregaços (presença de células endocervicais colunares e/ou metaplásicas) 4 .

O uso do swab de algodão para o preparo de esfregaços colpocitológicos já vem sendo investigado há várias décadas. Em 1947, Pund et al. ${ }^{9}$ descreveram sete casos de carcinoma préinvasor detectados por meio de esfregaços endocervicais preparados com swab de algodão e salientaram a importância da realização da colheita endocervical para o diagnóstico de carcinomas incipientes. Os resultados dos estudos que se seguiram, porém, são controversos e divergem com relação à validade do uso do swab de algodão.
Johansen et al. ${ }^{13}$ concluíram que a adição do swab de algodão à espátula de Ayre aumenta a detecção das lesões precursoras e invasoras. McCord et al. ${ }^{14}$, ao considerarem os custos para o rastreamento em massa em mulheres nãográvidas, recomendaram o uso da combinação espátula de Ayre modificada-swab de algodão. Smith-Levitin et al. ${ }^{15}$ concluíram que a combinação espátula de Ayre-swab de algodão é mais satisfatória para a colheita em gestantes pelo fato de possuir menor custo, ser segura e identificar a mesma proporção de anormalidades que os demais métodos.

O uso isolado do swab de algodão no preparo do esfregaço (coleta na ectocérvice e na endocérvice) foi desaconselhado por outros autores. Os motivos são a sua deficiência na captação de células e o aumento dos resultados falso-negativos ${ }^{16}$. Rubio ${ }^{17}$, utilizando microscopia eletrônica, descreveu que muitas células ficam presas nas fibras de algodão e não são transferidas (passivamente) para a lâmina.

O benefício do umedecimento prévio do algodão na captação de células endocervicais também já havia sido investigado por Kivlahan e Ingram ${ }^{18}$. Em uma amostra inicial que incluiu 533 esfregaços preparados com a combinação espátula de Ayre-swab de algodão seco e 241 preparados com a combinação espátula de Ayre-swab de algodão úmido, eles não observaram obtenção de maior número de células endocervicais com o umedecimento do algodão. A intervenção introduzida por eles que levou a um aumento significativo de células endocervicais foi o uso de uma espátula com ponta alongada ${ }^{18}$. Apesar do menor tamanho da amostra, alguns dos nossos achados foram semelhantes aos deste estudo. $\mathrm{Na}$ investigação da presença e grau de sangramento, não encontramos vantagem de nenhum dos métodos. Com relação ao aumento da obtenção de células endocervicais, não encontramos beneficios com a adição do swab de algodão, seja seco ou úmido. Isso nos permite concluir que, principalmente quando as colheitas forem realizadas por profissionais em treinamento e na ausência de outro dispositivo de coleta endocervical mais eficiente, é mais econômico utilizar apenas a espátula de Ayre, mesmo estando ciente da limitação do seu uso isolado.

\section{SUMMARY}

Purpose: to investigate if the addition of a cotton "swab" to the Ayre spatula and its previous moistening with physiologic saline solution increase the obtention of endocervical cells in 
colpocytologic smears.

Methods: a random and single-blind diagnostic study was performed, involving three techniques of collection (Ayre spatula, combination of Ayre-dry cotton swab spatula and combination of Ayre-moist cotton swab spatula). A total of 307 smears prepared by Medicine students and residents of Gynecology and Obstetrics were evaluated.

Results: there was no significant increase in the number of endocervical cells (columnar and/or metaplastic), obtained with the addition of dry swab $(p=0.2)$ or with the addition of a moistened swab $(p=0.8)$.

Conclusions: the author concluded that mainly when the collections were performed by trainee professionals and in the absence of other more effective endocervical collecting device, it is more economical to use only the Ayre spatula to prepare the smear.

KEY WORDS: Colpocytology. Uterine cervix: preoncoplastic lesion. Uterine cervix: cancer screening.

\section{Agradecimentos}

Aos estudantes de Medicina, Fisioterapia e Terapia Ocupacional da FCMMG e aos residentes de Ginecologia e Obstetrícia da Maternidade Odete Valadares que participaram na organização e execução do Mutirão de Saúde da Mulher em Bambuí.

\section{Referências}

1. Instituto Nacional do Câncer. Estimativa da incidência e mortalidade por câncer no Brasil: 1998. Rio de Janeiro: S.L.1998.

2. Campion MJ. The adequate cervical smear: a modern dilemma. J Fam Pract 1992; 34: 273-5.

3. Van der Graaf Y, Zielhuis GA, Vooijs GP. Cervical cancer mortality in the Netherlands. Int $\mathrm{J}$ Epidemiol 1988; 17: 270-6.

4. Kurman RJ, Solomon D. O sistema Bethesda para o relato de diagnóstico citológico cervicovaginal. Tradução de Dalton de Freitas Santoro; revisão técnica de Carmen Lúcia de Freitas Santoro. Rio de Janeiro: Revinter, 1997.

5. The 1988 Bethesda system for reporting cervical/ vaginal cytologic cytologic diagnosis; developed and approved at the National Cancer Institute. Workshop, Bethesda, Maryland, USA, December 12-13, 1988. Acta Cytol 1989; 33: 567-75.

6. Vooijs GP, Elias A, Van der Graaf Y, Poelen-Van de Berg M. The influence of sample takers on the cellular composition of cervical smears. Acta Cytol 1986; 30: 251-7.

7. Buntinx F, Knottnerus JA, André J, Crebolder HF, Essed GG. The effect of different sampling devices on the presence of endocervical cells in cervical smears; a systematic literature review. Eur J Cancer Prev 1994; 3: 23-30.

8. Boon ME, Alons-Van Kordelaar JJM, Rietveld-Scheffers PEM. Consequences of the introduction of combined spatula and cytobrush sampling for cervical cytology; improvements in smear quality and detection rates. Acta Cytol 1986; 30: 264-70.

9. Pund ER, Nieburgs HE, Nettles JB, Caldwell JD. Preinvasive carcinoma of the cervix uteri; seven cases in which it was detected by examination of routine endocervical smears. Arch Pathol 1947; 44: $571-7$.

10.Elias A, Linthorst G, Bekker B, Vooijs PG. The significance of endocervical cells in the diagnosis of cervical epithelial changes. Acta Cytol 1983; 27: 225-9.

11.Eisenberger D, Hernandez E, Tener T, Atkinson BF. Order of endocervical and ectocervical cytologic sampling and the quality of the Papanicolaou smear. Obstet Gynecol 1997; 90: 755-8.

12.Saitas VL, Hawthorne C, Cater J, Bibbo M. Singleslide versus double-slide Pap smear: a comparative study. Diagn Cytopathol 1995; 12: 320-2.

13.Johansen P, Arffmann E, Pallesen G. Evaluation of smears obtained by cervical scraping and an endocervical "swab" in the diagnosis of neoplastic disease of the uterine cervix. Acta Obstet Gynecol Scand 1979; 58: 265-70.

14.McCord ML, Stovall TG, Meric JL, Summitt RL, Coleman SA. Cervical cytology: a randomized comparison of four sampling methods. Am J Obstet Gynecol 1992; 166: 1772-9.

15.Smith-Levitin M, Hernandez E, Anderson L, Heller P. Safety, efficacy and cost of three cervical cytology sampling devices in a prenatal clinic. J Reprod Med 1996; 41: 749-53.

16.Shen JT, Nalick RH, Schlaerth JB, Morrow CP. Efficacy of cotton-tipped applicators for obtaining cells from the uterine cervix for Papanicolaou smears. Acta Cytol 1984; 28: 541-5.

17.Rubio CA. The false negative smears; the trapping effect of collecting instruments. Obstet Gynecol 1977; 49: 576-80.

18.Kivlahan C, Ingram E. Improved yield of endocervical cells on Papanicolaou smears in a residency setting. J Fam Pract 1985; 20: 381-5. 